\title{
Demografia dos povos indígenas: os Censos Demográficos como ponto de vista*
}

\author{
Marden Barbosa de Campos* \\ Bárbara Roberto Estanislau**
}

Os Censos Demográficos constituem uma das principais fontes de informações para estudos quantitativos sobre a população brasileira. Isso se deve tanto à amplitude da investigação em termos de cobertura espacial quanto ao volume de quesitos utilizados na pesquisa. Nas últimas décadas os Censos também se tornaram um instrumento primordial para estudos sobre os povos indígenas no Brasil (IBGE, 2010).

O objetivo desse ensaio é apresentar reflexões acerca do Censo Demográfico como instrumento de pesquisa dos povos indígenas no Brasil, confrontando suas potencialidades de análise, assim como algumas de suas limitações para estudos demográficos sobre essas populações. Será enfatizada a importância, para a investigação de características étnicas nos Censos Demográficos, de uma avaliação do instrumento de investigação, buscando compreender sua adequação para o estudo das especificidades apresentadas por esse segmento populacional.

Longe de desqualificar a informação, o debate em torno dos processos de construção da informação visa delimitar precisamente o objeto de que tratam essas informações, qualificando-as ainda mais enquanto instrumento de investigação. À medida que conhecemos a forma como foi produzida a informação, quais os agentes envolvidos em sua produção, as perguntas legitimadoras dos processos produtivos, dentre outros aspectos, aumenta a nossa segurança de que a informação refere-se a algum evento cuja manifestação foi “capturada" por uma operação de coleta.

\footnotetext{
* 0 texto reflete o ponto de vista dos autores e não necessariamente de suas instituições.

** Departamento de Sociologia da Universidade Federal de Minas Gerais (UFMG), Belo Horizonte-MG, Brasil (mardencampos@ gmail.com).

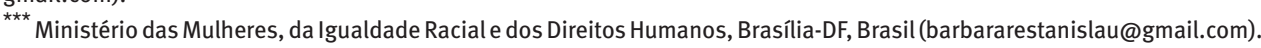




\section{Desafios para a mensuração dos fatos sociais}

A produção de informações sobre os "fatos sociais" é fruto de um arranjo institucional que qualifica, legitima e constrói tanto o processo de produção quanto a natureza da informação por ele produzida. Os números são importantes na vida social atual não só pelo que apresentam, mas também pelo fato de que concordamos em agir a partir deles. Para além de serem confiáveis, os números precisam ser aceitos como confiáveis. Nesse sentido, eles se ancoram em discursos legitimadores que atribuem valor ao que deve ou não ser pesquisado e a forma como isso pode ser feito (DESROSIERES, 2004).

A forma predominante hoje no Brasil de produção de informações sobre população, juntamente com os registros administrativos - Registro Civil, Sistema de Informações sobre Mortalidade, Sistema de Informações sobre Nascidos Vivos, dentre outros - é feita por meio de pesquisas domiciliares. Estes levantamentos seguem, em geral, um modelo de entrevista baseado em perguntas estruturadas e respostas categorizadas, que podem ser auto ou alterdeclaradas, dependendo de a unidade de investigação ser o domicílio, o indivíduo ou ambos, como no caso dos Censos. Nesse tipo de modelo, as respostas adquirem um "alto estatuto" de verdade, baseado na confiança em uma objetividade e imparcialidade do processo de pesquisa.

Os conceitos que norteiam o desenho do questionário dos Censos Demográficos são baseados em tipos de indivíduo típico, a que podemos chamar, nos termos estritos deste ensaio, de "brasileiro médio": aquele que reside em domicílios, reconhece outros moradores do mesmo domicílio, sabe das entradas e saídas de "recursos" ao domicílio (água, energia, lixo, renda, migrantes), da condição de posse do local, de sua divisão interna, dos bens materiais presentes, assim como reconhece as categorias de município, país e unidade da federação. Sobre os moradores, o indivíduo que os Censos buscam entrevistar precisa reconhecer sua idade e as dos demais moradores do domicílio, em termos de anos ou meses, além de suas cores ou raças investigadas, o sistema escolar seriado a que a maior parte dos brasileiros frequenta ou frequentou e o sistema de trabalho vigente no país. Ele precisa aceitar que variações de certas características físicas podem ser encaradas como deficiências, saber contabilizar o número de filhos das mulheres do domicílio, assim como atribuir idade e sexo a esses filhos.

Embora os questionários dos Censos incorporem cada vez mais possibilidades de resposta que se aproximam das formas de organização social de alguns povos indígenas, eles captarão melhor, obviamente, as características daqueles indígenas que mais se assemelham ao que estamos aqui chamando de "brasileiro médio". Evidentemente, para os que se distanciam da média apenas ligeiramente, também há possibilidades e variações de respostas, uma vez que todos os quesitos dos Censos permitem múltiplas opções de respostas. Contudo, essas opções também são baseadas em um distanciamento médio (ou padrão) do que se espera encontrar durante a coleta das informações.

Por outro lado, aqueles indivíduos cuja organização social ou o horizonte cognitivo diferem substancialmente dos conceitos utilizados nos Censos possivelmente terão sua 
captação prejudicada na pesquisa. Importante ressaltar que isso vale também para outros grupos étnicos, estrangeiros ou mesmo grupos socioeconômicos menos favorecidos.

Podemos usar como exemplo a investigação da idade na população. Entre a maioria da população não indígena do Brasil, coberta em grande parte por registros de nascimento e inserida em um processo educacional padronizado, é quase uma evidência que um indivíduo saiba sua idade. Por isso, conforme destaca Nobert Elias (1998) em seu estudo Sobre o tempo, "é com assombro" que descobrimos que existem sociedades em que indivíduos não sabem dizer qual é a sua idade. Segundo o autor, nós (os ocidentais) possuímos uma estrutura de personalidade dotada de percepção apuradíssima do tempo, a qual não podemos impor a grupos populacionais que não estão inteiramente submetidos a essa percepção (ELIAS, 1998). Conforme destacam Pagliaro, Azevedo e Santos (2005), os povos indígenas têm maneiras próprias de classificar a idade das pessoas, além de possuírem uma variedade de sistemas numéricos ainda pouco conhecidos.

Se essa afirmação já provoca desconfiança quanto ao levantamento de uma variável à qual atribuímos certa simplicidade, o que dizer em relação à investigação dos temas família, domicílio, nupcialidade, migração, trabalho e deficiência entre populações com visões de mundo discrepantes das que constam nos manuais do Censo?

Considerando as transformações experimentadas pelos povos indígenas ao longo dos vários séculos de colonização, incluindo a urbanização e a exposição à escola, é provável que a maior parte dos indígenas registrados pelo Censo Demográfico de 2010, por exemplo, compartilhe as noções presentes nos quesitos investigados. Por outro lado, dos 786 mil indígenas registrados com cinco anos ou mais de idade, 137 mil (17,4\% do total) não falavam português no domicílio (IBGE, 2010). Entre alguns desses indivíduos, pode-se supor que tenha havido um entendimento diferenciado das perguntas do Censo, com possíveis reflexos nos resultados divulgados. Nos casos em que houve uso de tradutores para entrevistar indígenas, esses problemas podem ter sido amenizados, ainda que não saibamos se os tradutores possuem um entendimento das perguntas mais próximo dos indígenas entrevistados ou dos não indígenas que elaboraram o questionário.

Por isso, acredita-se que o Censo captará com maior precisão as características dos povos indígenas que se aproximaram mais do conceito de "brasileiro médio" que embasou a construção dos questionários. Embora saibamos que parte das perguntas de cada Censo baseia-se nos resultados dos Censos anteriores, esse fato agrava ainda mais os problemas de captação de populações minoritárias, cujos números são eclipsados pela média das respostas de cada quesito.

\section{As estatísticas e os fatos sociais}

Dado o caráter altamente reflexivo encontrado nas ciências sociais, os resultados de pesquisas e estudos e a construção de teorias sobre fenômenos sociais interferem na conformação das sociedades e na identificação dos indivíduos com esta realidade. Nesse 
sentido, quando utilizamos categorias pré-concebidas nos estudos de população, não sabemos em que medida estamos descobrindo algo ou se estamos criando os próprios fenômenos que queremos estudar.

Quando utilizamos o termo "indígena” para tratar de toda uma categoria populacional, corremos o risco de criar uma "entidade" especial. Incorre-se no tipo de problema destacado por Wolf (1997) de se "transformar nomes em coisas". A diversidade de etnias existentes no Brasil e a heterogeneidade encontrada entre elas certamente tornariam difícil enquadrar indivíduos em uma mesma categoria genérica com a arbitrariedade com que 0 fizeram os europeus que aqui chegaram. Devido ao fato de essa categoria continuar a ser utilizada ainda hoje, tanto no senso comum como na categoria analítica, é "quase óbvio" que tenha se tornado uma opção de resposta dos Censos Demográficos.

Contudo, embora o Censo possua elevado potencial analítico e venha contribuindo enormemente para o conhecimento de parte da realidade indígena do país nos últimos anos, usar a categoria indígena sem tornar o restante do questionário do Censo sensível à diversidade dessa população limita o instrumento como fonte de informação. 0 estudo de Pereira et al. (2009) sobre os Xavante é um exemplo de como os modos de habitação indígena são difíceis de serem enquadrados nos tipos de domicílio utilizados nos Censos.

Nossos campos disciplinares, com suas lógicas discursivas e arcabouços conceituais, produzem instrumentos intelectuais nos quais se incluem os métodos de experimentação. O Censo é um exemplo de instrumento de investigação a alimentar discursos, reificar uma ideia de realidade e perpetuar estruturas de poder, conforme será discutido adiante.

\section{Desafios para a mensuração de marcadores culturais}

Uma das questões mais complexas que surge do exercício de uma demografia dos povos indígenas talvez seja aquela que, enganosamente, aparenta possuir maior "simplicidade": como identificar os indígenas utilizando os Censos?

A mensuração de caracteres culturais como raça ou etnia é difícil pelo fato de possuírem um nível de subjetividade maior do que o encontrado, por exemplo, na mensuração da idade ou do sexo dos entrevistados. Isso torna-se ainda mais complexo quando consideramos que um censo investiga apenas atributos que, a princípio, são inteligíveis para aqueles que elaboram o questionário da pesquisa, que no Brasil são indivíduos não indígenas

Um procedimento demográfico como a realização de um censo busca atingir um realismo estatístico, como experimento lógico, que possa atribuir aos dados coletados um status de verdade. Desse modo, esse tipo de procedimento, que necessita de precisão nos identificadores construídos, torna-se extremamente complexo quando tratamos de marcadores culturais.

Embora os demógrafos beneficiem-se dos debates a respeito do termo "cultura", suas análises, em geral quantitativas, não se fundamentam em uma teoria ampla e abrangente sobre cultura (KERTZER, 1997). Os demógrafos precisam construir indicadores de "cultura" 
que sejam passíveis de compor arcabouços explicativos da dinâmica da população, satisfazendo-se com aproximações do tema que sejam passíveis de formalização. Como os indicadores de cultura são fortemente influenciados por construções políticas e ideológicas, não é simples para a demografia tratar de questões ligadas ao tema. Esse fato torna-se ainda mais problemático quando se consideram as relações de poder presentes na sociedade na elaboração dos instrumentos de pesquisa.

\section{Os Censos e 0 aparato estatal}

A categoria de resposta "indígena" para o quesito de cor ou raça dos Censos é fruto de uma continuidade histórica, cuja herança imperialista e colonial permanece atuante ainda hoje. Assim como em nosso passado colonial, o termo "indígena" continua sendo um ponto de vista parcial e etnocêntrico. Do mesmo modo, são etnocêntricas nossas metodologias, nossos métodos de pesquisa, nossas teorias e o estilo de escrita que usamos para escrever sobre os Censos.

0 conceito abstrato de "brasileiro médio" utilizado neste texto ancora-se em um projeto de identidade nacional que, embora venha se modificando, permanece tendendo para a uniculturalidade.

Axelsson e Skold (2011) destacam a complexa relação existente, na produção de uma demografia dos povos indígenas, entre identidade e estatística. Segundo os autores, há sempre uma associação próxima entre a enumeração, a classificação e as relações de poder. Embora os demógrafos não sejam comumente contestados sobre as ligações de seus métodos de trabalho e os instrumentos de poder, Axelsson e Skold (2011) afirmam que a demografia dos povos indígenas situa-os exatamente na interseção entre essas forças.

Mesmo as medidas estatísticas mais simples, como uma "média", estão ancoradas em visões de mundo particulares, conforme alerta Alain Desrosieres (1984). Estas medidas, principalmente quando divulgadas por institutos oficiais, moldam os pontos de apoio sobre os quais se estruturam os discursos que dão estabilidade e legitimam as organizações políticas estatais. 0 Estado configura-se, desse modo, como uma instância legítima, "necessária” e "benéfica” para a maioria de seus cidadãos, mesmo que as minorias enfrentem problemas de exclusão e discriminação. Nesse sentido, não há como dissociar a pesquisa censitária de populações minoritárias da supremacia exercida, sobre essas, pelas populações dominantes dentro de determinada organização estatal (QUIJADA, 2000).

De certa maneira, o Estado moderno utiliza ferramentas que produzem controle, nos moldes da alegoria de "Panóptico" descrita por Michael Foucault, "iluminando" aqueles que estavam "protegidos" na escuridão (FOUCAULT, 1979, 2000). O Estado moderno conta e descreve a população que governa e para a qual desenha suas políticas. Sendo a população, juntamente com o território, a base do Estado moderno, é questão de princípio a necessidade de contá-la e de produzir meios de conhecer suas características. Ao mesmo tempo, contar torna-se um artifício de medir, de controlar, de saber para quem se governa 
e o que se governa. Como sistema de organização política constituído a partir de um território que tem o povo como soberano, o Estado moderno seria a fonte legítima e única da autoridade, ao qual a população deve lealdade. Tal asserção culmina no conceito moderno de cidadania, sendo o Estado a "nação dos cidadãos". Anderson (1991) chega a atribuir aos censos a condição de pilar do Estado moderno, na medida em que, juntamente com o mapa e o museu, seria instrumento de poder que legitimaria a existência do Estado e do nacionalismo contemporâneo.

0 desafio de estudar os povos indígenas vem do fato deles possuírem características e relações com o mundo que diferem do conceito de cidadão que normalmente é preservado pelo Estado moderno. Isso se reflete nos levantamentos populacionais e pesquisas censitárias. Por isso, os Estados que pleiteiam uma identidade unicultural acabam ancorando-se sobre instrumentos homogeneizantes (QUIJADA, 2000).

Não se quer dizer que o Censo seja um instrumento construído com o objetivo velado de assimilação e aumento da opressão sobre os diferentes, ainda que tenha participação importante nesses processos. Também não afirmamos que o Censo piora a "qualidade" do Estado. Um Estado sem nenhuma informação possui as mesmas fragilidades de um Estado com uma única fonte de informação. 0 que se quer enfatizar é que a incorporação da diversidade étnica, linguística e cultural na investigação censitária, entre outros aspectos, faria parte da aceitação por parte do Estado da pluralidade de culturas dos indivíduos que habitam o território nacional. No caso brasileiro, isso pode ser percebido nos Censos Demográficos, quando se começa a investigar com mais detalhes, como em 2010, características que permitem conhecer a diversidade de etnias e línguas indígenas faladas no país. Do mesmo modo, o esquecimento dessa diversidade nas pesquisas populacionais acusaria parte do processo de negligenciamento dessa realidade.

As transformações por que passam as instituições modernas, no sentido de aceitar a diversidade étnica e a pluralidade cultural, são relativamente recentes no Brasil. No último meio século de história do país, apenas após a Constituição de 1988 a categoria indígena foi reinserida nos Censos Demográficos, depois de terem sido excluídas dos levantamentos de 1970 e 1980. Aumentaram assim, por meio das estatísticas, as possibilidades de esses povos se tornarem mais visíveis, contribuindo para pautar seus direitos perante o Estado, o que ainda não ocorreu com outros povos e comunidades tradicionais.

\section{Ampliação da investigação dos indígenas nos Censos Demográficos do Brasil}

Apesar das críticas às limitações dos Censos para estudo de determinados aspectos dos povos indígenas, reconhece-se que a incorporação do tema e a ampliação da investigação ocorrida em 2010 constituíram um ganho enorme para os estudiosos e para os povos indígenas em si. Conforme destacam Santos e Teixeira (2011), trilha-se no Brasil uma bem-sucedida trajetória de incluir os indígenas nas estatísticas nacionais, com implicações importantes para as políticas públicas direcionadas a estes povos. 
O Censo confere visibilidade a diversos povos indígenas, sendo uma ferramenta imprescindível para identificar alguns segmentos dessa população, como aqueles que vivem em áreas urbanas, especialmente em grandes metrópoles. Contudo, é preciso que sejam superados os problemas para a captação, entre os povos indígenas, da diversidade de formas de habitação, relações de parentesco, padrões de nupcialidade, atividades produtivas, processo de escolarização, entre outros aspectos.

Embora o presente artigo tenha um caráter mais reflexivo do que propositivo, pode-se pensar, por exemplo, na questão dos quesitos da nupcialidade dos indígenas como tema a ser aprimorado nas novas rodadas censitárias. Assim como no caso da "espécie do domicílio" investigada no Censo de 2010, que, quando localizado em terras indígenas, acrescentavam-se as opções de resposta "oca ou maloca”, nas terras indígenas seria possível incorporar múltiplos arranjos conjugais.

Os últimos Censos têm fornecido dados consistentes e comparáveis sobre os indígenas, destacando sua vulnerabilidade em relação a outros grupos populacionais, o que se expressa, por exemplo, nos mais elevados níveis de mortalidade infantil (IBGE, 2005).

Por isso, nossa pretensão aqui é enfatizar a necessidade de ampliação e aprimoramento dessas estatísticas. 0 Censo brasileiro precisa incorporar ainda mais a pluralidade étnica da população brasileira, com sua diversidade de culturas e modos de viver. É necessário aprimorar o levantamento censitário, incluindo a perspectiva dos investigados nas discussões sobre o desenho da operação.

As informações demográficas não são apenas um produto dos demógrafos, mas também o resultado de negociações entre os institutos de estatística e a sociedade, que designam o que, como e com que frequência um tema será pesquisado.

Não queremos impor aos povos indígenas uma forma de pensar ocidental ou "não indígena" e muito menos uma "pureza pré-colombiana”. Queremos pensar em que tipos de dados precisamos produzir para os povos indígenas na situação em que se encontram hoje, com suas questões atuais e suas perspectivas de futuro.

Um exemplo de “descolonização" da construção de dados oficiais são os Índices do Bem Viver utilizados no Equador (ROSERO, 2015). Eles levam em conta preceitos de bem-estar que se assemelham ao modo de vida dos povos indígenas que ali habitam. Essas mudanças estatísticas decorreram da construção de uma nova Constituição daquele país que abarcava outras possibilidades de conceitos de vida e bem-estar (ECUADOR, 2008). 0 caso dos equatorianos é importante como exemplo de possibilidade de construção de estatísticas e de Estados mais inclusivos.

Já avançamos muito nos quesitos dedicados à investigação da população indígena. O Brasil avança em direção a uma cada vez maior "sensibilização" dos questionários do Censo, direcionados para a identificação das características de toda a população, para a diversidade de modos de vida dos povos indígenas do Brasil. É preciso preservar as conquistas até aqui alcançadas e manter o diálogo entre aqueles dedicados ao tema, especialmente com os que se encontram mais próximos e são mais sensíveis à produção 
de informações étnicas, os próprios indígenas. Seguindo no trilho de uma maior inserção dos indígenas nas estatísticas públicas do país, estamos dando um passo importante em termos de redução de sua vulnerabilidade social.

\section{Referências}

ANDERSON, B. Imagined communities: reflections on the origin and spread of nationalism. London and New York: Verso Books, 1991.

AXELSSON, P.; SKÖLD, P. Introduction. In: AXELSSON, P.; SKÖLD, P. (Ed.). Indigenous peoples and demography: the complex relation between identity and statistics. New York, Oxford: Berghahn, 2011.

DESROSIERES, A. La política de los grandes números. Barcelona: Editorial Melusina, 2004.

ECUADOR. Constituição 2008. Constitución política del Ecuador, 2008. Disponível em: «www. oei.es/formaciondocente/legislacion/ECUADOR/GENERAL/CONSTITUCION.pdf〉. Acesso em: 13 nov. 2015.

ELIAS, N. Sobre o tempo. Rio de Janeiro: Jorge Zahar, 1984.

FOUCAULT, M. Microfísica do poder. Organização e tradução de Roberto Machado. Rio de Janeiro: Edições Graal, 1979. Vozes, 2000

Vigiar e punir: nascimento da prisão. Trad. Raquel Ramalhete. 23. ed. Rio de Janeiro:

IBGE - Instituto Brasileiro de Geografia e Estatística. Tendências demográficas: uma análise dos indígenas com base nos resultados da amostra dos censos demográficos 1991 e 2000 . Rio de Janeiro: Coordenação de População e Indicadores Sociais, 2005 (Série Estudos e Pesquisas).

Características gerais dos indígenas: resultados do universo. Rio de Janeiro: IBGE, 2010.

KERTZER, D. The proper role of culture in demographic explanation. In: JONES, G. W.; DOUGLAS, R. M.; CALDWELL, J. The continuing demographic transition. Oxford: Oxford University Press, 1997.

PAGLIARO, H.; AZEVEDO, M. M.; SANTOS, R. V. (Org.). Demografia dos povos indígenas no Brasil. Rio de Janeiro: Editora Fiocruz/Abep, 2005.

PEREIRA, N. O. M. et al. Demography, territory, and identity of indigenous peoples in Brazil: the Xavante indians and the 2000 Brazilian national census. Human Organization, v. 68, n. 2, p. 166-180, 2009.

QUIJADA, M.; BERNAND, C.; SCHNEIDER, A. Homogeneidad y nación con un estudio de caso: Argentina: Siglo XIX y XX; Madrid: Consejo Superior de Investigaciones Científicas, Centro de Humanidades, 2000.

ROSERO, J. Hacia nuevas métricas del Buen Vivir em Ecuador. [S.d.]. Disponível em: «www. ecuadorencifras.gob.ec/documentos/web-inec/boletin/hacia_nuevas_metricas_del_buen_vivir. pdf〉. Acesso em: 13 nov. 2015.

SANTOS, R. V.; TEIXEIRA, P. O “indígena” que emerge do Censo Demográfico de 2010. Cadernos de Saúde Pública, Rio de Janeiro, v. 27, n. 6, p. 1048-1049, jun. 2011.

WOLF, E. R. Europe and the people without history. Berkeley, Los Angeles: University of California Press, 1997. 


\section{Sobre os autores}

Marden Barbosa de Campos é doutor em Demografia pelo Centro de Desenvolvimento e Planejamento Regional (Cedeplar) da Universidade Federal de Minas Gerais (UFMG). Professor do Departamento de Sociologia da UFMG.

Bárbara Roberto Estanislau é mestre em Demografia pela Universidade Estadual de Campinas (Unicamp). Analista técnica de políticas sociais do Ministério das Mulheres, da Igualdade Racial e dos Direitos Humanos.

\section{Endereço para correspondência}

Marden Barbosa de Campos

Universidade Federal de Minas Gerais

Departamento de Sociologia - Faculdade de Filosofia e Ciências Humanas

Av. Pres. Antônio Carlos, 6627, Pampulha

31270-901 - Belo Horizonte-MG, Brasil

Bárbara Roberto Estanislau

Esplanada dos Ministérios, Bloco A, 5ํㅜ e 9ํaa andares

70054-906 - Brasília-DF, Brasil

Recebido para publicação em 30/11/2015

Recomendado para publicação em 29/07/2016

Aceito para publicação em 12/10/2016 